\title{
O IMPERATIVO CATEGÓRICOO COMO REALIZAÇÃO DA NECESSIDADE LÓGICA DA RAZÃO
}

\author{
The Categorical Imperative As Accomplishment Of \\ The Logical Need Of The Reason
}

\author{
Andréa Luisa Bucchile Faggion ${ }^{1}$
}

\section{Resumo}

O imperativo categórico, princípio supremo da moralidade, é apresentado por Kant como um princípio sintético, portanto, como uma proposição cuja validade não se estabelece com o mero recurso ao princípio de não-contradição. Neste artigo, argumento que, quando levamos em consideração o exame do simples uso lógico da razão, feito por Kant na Crítica da Razão Pura, torna-se no mínimo plausível a possibilidade de que a fórmula do princípio moral, na medida em que contém uma condição incondicionada para ações, traga em si mesma a justificativa da obrigação que impõe a seres racionais em geral, ou seja, estou sugerindo que textos da primeira Crítica possam demonstrar que bastaria uma análise do conceito de um ser racional dotado de vontade e do conceito de um princípio incondicional das ações para que pudéssemos estabelecer a necessidade da relação entre eles, sendo dispensável um terceiro termo, sempre necessário para a justificativa de princípios sintéticos.

Palavras-chave: Kant; Imperativo categórico; Postulado lógico; Justificativa.

\section{Abstract}

The categorical imperative, supreme principle of morality, is presented by Kant as a synthetic principle, therefore, as a proposal whose validity is not established with the mere resource to the non-contradiction principle. In this article, I argue that, when we take in consideration the examination of the simple logical use of the reason, made by Kant in the Critique of Pure Reason, at the very least becomes reasonable the possibility of the formula of the moral principle, to the extent that it contains an unconditioned condition to actions, to bring inside itself the justification of the obligation that imposes the rational beings in general, which means I am suggesting that texts from the first Critique can demonstrate that it would be enough to have an analysis of the concept of a rational being endowed with will and of the concept of an unconditional principle of the actions so that we could establish the necessity of the relation between them, being dispensable a third term, always necessary for the justification of synthetic principles.

Keywords: Kant; Categorical imperative; Justification, Logic postulate.

1 Doutoranda pela Universidade Estadual de Campinas / Secretária Administrativa da Seção de Campinas da Sociedade Kant Brasileira.

E-mail: andreafaggion@bol.com.br 


\section{Introdução}

Uma vez que se aceite que o escopo da moralidade sejam deveres incondicionais impostos pela razão, há um certo consenso acerca da precisão da fórmula em que Kant expõe o princípio subjacente a esses deveres. O foco das disputas entre os advogados e os desafiantes da filosofia moral kantiana tende assim a se concentrar na questão da possibilidade de se provar a validade de tal princípio e, conseqüentemente, a própria legitimidade das obrigações morais. No entanto, em vez de se debruçar sobre uma avaliação dos caminhos percorridos por Kant em busca da fundamentação do princípio maior da moralidade, este artigo pretende seguir uma via mais heterodoxa e analisar a própria formulação do princípio, colocando em pauta, com auxílio da primeira Crítica, uma reflexão em torno da possibilidade de que essa fórmula já traga em si mesma sua justificativa, ao contrário do que pensava Kant.

Como a Crítica da Razão Prática não apresenta maiores divergências na obtenção da fórmula do princípio moral em relação à Fundamentação da Metafísica dos Costumes, obra em que Kant pela primeira vez se deteve no ponto e com maior riqueza de detalhes, irei concentrar minha análise nesta última, me restringindo, obviamente, às duas primeiras seções, que contêm a exposição da fórmula.

\section{O tipo de lei operante no querer moral}

\section{A vontade moralmente boa e o dever}

Analisando juízos morais executados pela razão em seu uso comum, na I seção da Fundamentação, Kant descobre que a ação moralmente boa é apenas e tão somente aquela praticada pelo reconhecimento do dever moral de praticar tal ação. Uma ação conforme ao dever pode ser praticada "por inclinação", "com intenção egoísta" ou "por dever" (Cf. FMC, I, §9, BA 8-9). Kant não analisa as ações contrárias ao dever, dizendo que, por estarem em contradição com ele, não levantariam a questão de saber se foram praticadas por dever. Isto pode dar margem à objeção de que ele estaria falhando em não distinguir entre ações subjetivamente e objetivamente conforme ao dever. Se o sujeito faz algo contra o dever objetivamente, mas pensa estar fazendo a coisa certa, ele poderia agir por dever. Mas talvez o texto de Kant pudesse dar ensejo a esta distinção. Ele se refere, não simplesmente a ações contrárias ao dever, mas a ações "reconhecidas [erkannt] como contrárias ao dever" (FMC, I, §9, BA 8). Todavia, este não deve ser o ponto de Kant, porque, ao que parece, se o sujeito age por dever, mas falha em reconhecer o dever, seria melhor dizer que ele pensa agir por dever (ou age por engano). Neste momento, o sujeito não foi apto a reconhecer a moralidade e temporariamente não é imputável.

Kant considera que ações praticadas por inclinação imediata não podem ser tão facilmente distinguidas de ações por dever como aquelas que são praticadas apenas com intenção egoísta. Ao que parece, o ponto é que não é difícil determinar o estatuto moral da ação praticada apenas mediatamente por inclinação (ALUSON, 1990, p.109). Kant cita como exemplo o comerciante esperto que não sobe os preços a compradores inexperientes apenas quando o movimento é grande. A questão parece ser que, quando se trata de julgar alguém que teria agido por inclinação imediata, não fica tão claro por que a ação não teria valor moral e, por conseqüência, qual a especificidade do "por dever" para que só ele tenha esse valor. Possivelmente, isto se dá porque a ação praticada por inclinação imediata também parece ter valor em si mesma.

No primeiro exemplo oferecido por Kant sobre o ponto, ele afirma: "Os homens conservam a sua vida conforme ao dever, sem dúvida, mas não por dever" (FMC, I, §10, BA 9-10). Poderia parecer curioso que, depois de chamar a atenção para a dificuldade de distinguir ações por inclinação imediata de ações por dever, ele afirme, com tanta segurança, que o cuidado com a vida por parte dos homens não se deve ao dever, mas à inclinação imediata. Entretanto, isto abona a interpretação oferecida aqui. $\mathrm{O}$ problema não seria 0 de saber que motivo tem cada ação, se é que de alguma forma isto é possível, mas sim saber conceitualmente por que ações por inclinação imediata não têm valor moral.

Para lidar com esse problema, Kant monta, no segundo exemplo, um cenário hipotético de ação por inclinação imediata e, diga-se de passagem, não faz isto muito bem. Ele fala de pessoas dispostas a fazer caridade sem nenhum outro mo- 
tivo. 0 único prazer que advém do gesto é o próprio fato de terem espalhado alegria. Neste ponto, Kant macula o exemplo acrescentando que o contentamento dos outros torna essas pessoas felizes "enquanto este é obra sua" (FMC, I, §11, BA 10). Como Allison bem observou: "isso sugere que 0 que os motiva não é tanto uma preocupação desinteressada com o bem estar dos outros, quanto o desejo de ser a fonte deste bem estar" (1990, p. 110). Felizmente, não é difícil consertar o exemplo. Basta suprimir a oração supracitada para mantermos a intenção de Kant: expor um tipo de motivação baseado no prazer da própria ação, sem segundas intenções.

O problema com esse tipo de motivação fica claro com a análise do comportamento das pessoas que agem dessa forma. Quando seu temperamento, por algum motivo, é alterado, não fazem mais caridade. Só faziam sob aquela condição que se extinguiu. Além do mais, parece ser bastante evidente que ações por inclinação imediata não são necessariamente conformes ao dever, pois todos concederiam que alguém, por inclinação imediata, pode, por exemplo, espalhar sofrimento à sua volta. É apenas um "feliz acaso", como Kant diz, que a inclinação coincida com o dever. Portanto, quem tem por princípio realizar suas inclinações pode se adequar ao dever ou não. 0 fundamental é que, no fim, embora o senso comum se incline a julgar de modo diferente, ações por inclinação, não importa se mediata ou não, sofreriam todas do mesmo mal. O que é relevante não é a tese de Kant do egoísmo presente nas duas (por isso, não a abordo), mas sim que ambas são condicionadas (a ação vale enquanto satisfaz uma inclinação) e disto resultaria, não genuíno valor moral (sempre incondicional), mas, no máximo, uma mera conformidade contingente ao dever.

\section{A determinação positiva da ação por dever}

Depois de determinar a ação por dever como uma ação que não é condicionada, no §14 da I seção, Kant está em condições de determinar positivamente a ação por dever, contrastando-a com as ações por inclinação. Em um primeiro momento, já podemos dizer que, como alguém pode ter uma intenção conforme ao dever (proporcionar alegria aos outros, por exemplo) sem agir por dever, ou seja, sem preocupações morais, não é na intenção que reside o valor moral das ações. Mais do que isso, a ação por dever não faria do propósito um móbil para a vontade (como acontece com 0 filantropo do começo do §11), porque então a ação seria condicionada pela inclinação, já que seria um objeto o motivo da ação, e não qualquer regra a qual a ação se conformasse. A pergunta de Kant é então a seguinte: "Em que é que reside pois este valor [moral], se ele não se encontra na vontade considerada em relação com o efeito esperado dessas ações?' (FMC, I, BA 13-4). A resposta de Kant, como já era de se esperar, é que reside no princípio da vontade, abstraindo dos fins ou da matéria da máxima: a vontade "terá de ser determinada pelo princípio do querer em geral quando a ação seja praticada por dever, pois lhe foi tirado todo o princípio material" (FMC, I, BA 14).

\section{A intenção das ações e a motivação moral}

Kant é bem claro, ao menos quanto a isto, no §14. Não se trata de dizer que ações morais não possuem um fim, mas sim que a inclinação pelo fim não é o que determina a ação quando ela deve possuir valor moral. Além disso, a presença de determinados fins não poderia ser o critério distintivo das ações morais ou praticadas por dever: uma "ação praticada por dever tem o seu valor moral, não na inten ção que com ela se quer atingir, mas na máxima que a determina" (BA13). É útil neste ponto estarmos atentos ao comentário de Beck ao Teorema I da Crítica da Razão Prática, cujo conteúdo é praticamente idêntico ao nosso ponto ${ }^{2}$. Segundo o comentador, Kant está preocupado em desqualificar apenas as máximas que são adotadas pelo seu conteúdo, isto é, aquelas em que a referência ao objeto é o fator determinante da ação, e não máximas que possuam objetos ou conteúdo empírico, pois estas são inevitáveis (BECK, 1960, p. 96 e também p. 118, 130 e 135) ${ }^{3}$. Na verdade, Kant mesmo é explícito quanto a isso na segunda Crítica: "é certamente inegável que todo o querer deve ter também um objeto [Gegenstand], por conseguinte, uma matéria [...] a matéria da máxima pode permanecer, mas não deve ser sua condição" (A 60-1, grifo meu. Cf. também, A 48-9).

A princípio, não se trata também de dizer que quem age moralmente (por dever), age para (com a intenção de) realizar o dever e não, por exemplo, para (com a intenção de) ajudar um 
amigo. Talvez, estaríamos confundindo dois níveis da ação, a motivação e a intenção. Afinal, também poderíamos dizer, se fosse o caso, que quem ajuda o amigo por inclinação, não quer ajudar o amigo, mas satisfazer a inclinação. O correto pode ser que digamos que quem quer ajudar o amigo, quer ou por inclinação ou por dever. A diferença entre os dois tipos de ação, quanto à intenção, é que a primeira é determinada pelo propósito mesmo, enquanto objeto da inclinação, e a segunda apenas por um princípio formal, embora não deixe de ter uma intenção. Esta é a tese defendida por Allison (1990, p. 190-8).

Ao que parece, a tese de Allison precisa de reparos, porque quem age moralmente realmente quer o propósito expresso no conteúdo de uma máxima como quero ajudar as pessoas, mas, como ele age por dever, devemos admitir que ele tem uma intenção superior, à qual ele subordina a intenção de ajudar as pessoas, e que determina esta última, ou seja, o sujeito moral tem uma máxima superior ou fundamental com uma intenção última: quero agir moralmente, seja lá qual for a circunstância. Allison parece que esteve desatento para a necessidade de uma teoria da hierarquia das máximas, com a existência de uma máxima fundamental determinando a adoção das outras, a qual indicamos acima no caso do agente moral. Em outro caso, a máxima fundamental seria algo como: quero realizar minhas inclinações (obter satisfação), em todas as circunstâncias, independentemente dos requerimentos da moral. Tem que estar sob meu poder a própria decisão de agir por dever $^{4}$ - o quer dizer que essa decisão mesma tem que poder estar contida em uma máxima minha, ou que eu tenho que poder ter como intenção agir por dever - se aí se encontra o valor moral das ações, do contrário, não há razão para a discussão sobre mérito e culpa que é o próprio discurso moral.

É importante esclarecer que o que chamo de máxima fundamental não precisa ser, e dificilmente é, expressamente formulado pelo agente. Entretanto, não se trata de uma especulação psicológica do tipo: inconscientemente o sujeito procurava $\mathrm{x}$ acima de tudo. A máxima fundamental seria apenas o produto de uma reconstrução lógica, que busca chegar a um termo último, da justificativa oferecida para uma ação. Pode ser entendida como o princípio subjetivo mais alto com o qual o agente se compromete logicamente ao agir. A atuação sob uma determinada máxima específica implicaria na aceitação de uma máxima superior e geral, da qual ela poderia ser derivada, uma vez apresentada a situação de ação. Por hipótese, a máxima fundamental poderia ser alterada. Tratar-se-ia de uma mudança radical na atitude moral do agente.

Voltando ao ponto, para esclarecer a tese de que não é a intenção que determina as ações morais, a esta altura bastante complicada, podemos recorrer à distinção entre dois sentidos de objeto para a qual Beck chama a atenção. Em um sentido, objeto significa "um real estado de coisas, uma coisa física e seus efeitos psicológicos que podem ser trazidos à existência pela ação" (1960, p. 92). Mas o termo "objeto" também pode se referir "a uma disposição interna da vontade, a um ato de decisão dela própria sem considerar a causalidade da vontade em trazer seus objetos (no primeiro sentido) à existência" (ibid. idem.). A máxima superior do agente moral terá então um propósito, mas um que não é objeto físico. Ela tem um objeto no segundo sentido apontado por Beck. Assim, intenção (matéria) e motivação moral da vontade (o por dever como motivação, ou o princípio formal como fator determinante da ação) se fundem na máxima fundamental (BECK, 1960, p. 120-1, 134 e 136). De modo que, podemos dizer que a tese de Kant de que não é o objeto (intenção) da máxima que determina a ação moral, se aplica apenas àquelas máximas subordinadas dotadas de um propósito que é um objeto no primeiro sentido. Estas máximas são necessárias em toda ação, já que de uma determinação tão geral quanto a máxima fundamental não se segue imediatamente uma ação, sempre particular. Realmente, máximas específicas são o objeto de análise adequado, caso Kant não queira cometer uma petição de princípio no §14, que ainda prepara o terreno para afirmar que a ação moral deve ser guiada por uma máxima fundamental como a que vimos descrevendo.

Mas talvez haja um problema nesta tese, que parece repousar na afirmação sobre uma intenção moral superior determinando a escolha de máximas subordinadas. Paton percebeu muito bem a dificuldade: "não deve ser suposto que a ação [e a máxima correspondente]é então querida somente como um meio para uma abstração vazia..." (1947, p. 75. Cf. também p. 115 e 166). As categorias de meio e fim, embora adequadas para quem tem a 
intenção última: obter satisfação; não se aplicam à atitude moral. De outra forma, teríamos máximas (e também ações) morais que não seriam boas em si mesmas, algo que Kant não admitiria (Cf. FMC, I, nota ao §14, BA 39, por exemplo). Querer uma máxima por dever é querê-la pelo seu valor intrínseco, portanto, não podemos dizer que agir moralmente seja um fim para o qual ajudar o amigo seria um meio. Em vez disto, ajudar o amigo é uma especificação (ou uma aplicação) da intenção mais geral de ser moral. Ajudar o amigo é agir moralmente. Todavia, se alguém ajuda o amigo por inclinação (mesmo imediata), pelo contránio, podemos distinguir entre agir e ter prazer na ação. Ajudar o amigo não é ter prazer, ajudar o amigo dá prazer. Este é o ponto. A ação é um meio de obter satisfação. Podemos dizer que uma coisa é a máxima, outra coisa é o efeito de seu objeto sobre a sensibilidade (ou uma coisa é a ação e outra seu efeito na sensibilidade), enquanto a adequação ao princípio formal do querer faz parte da ação (ou da máxima que a determina) mesmo (é uma característica dela): "é a condição da bondade da ação [ou da máxima], não obstante é um elemento da ação [ou da máxima] mesmo" (PATON, 1947, p. 76, 108, 134 e 186).

\section{A lei da boa vontade}

Nos §§16-7 da I seção, Kant procura a fórmula do princípio formal, ou a lei da vontade absolutamente boa que é, nos seres racionais imperfeitos, igual à vontade que age por dever. Por não poder ter um princípio que incorpore como incentivo o efeito da ação, caso em que a ação seria por inclinação, só resta a representação da lei em geral para exercer esse papel. O princípio que não toma em consideração nenhum efeito, dizendo respeito a uma vontade que não conta com nenhum estímulo à sua obediência, só pode expressar a lei universal em geral, sem nenhuma restrição à sua universalidade, isto é, "devo proceder sempre de maneira que eu possa querer também que a minha máxima se torne uma lei universal" (FMC, I, §17, BA 16). Este princípio, que ordena um tipo de ação (é um critério moral) e o motivo pelo qual as ações deste tipo devem ser praticadas (PATON, 1947, p. 117 e 186), é, portanto, o único incondicional, o que faz com que a boa vontade, definida por ele, seja o único bem incondicional ${ }^{5}$.
O princípio é a lei moral para nós e como Allison coloca: "agir por dever no sentido kantiano é apenas agir à luz do reconhecimento da lei moral como autoridade suprema ou, equivalentemente, como obrigando [binding] incondicionalmente" (Cf. p. 119).

\section{O imperativo categórico como princípio supremo da moralidade}

\section{O imperativo categórico e sua fórmula}

O princípio exposto acima em sua fórmula embrionária volta a aparecer, na II seção da Fundamentação, na forma do imperativo categórico. É sabido que cada seção da Fundamentação representa uma passagem. Agora não se trata mais de esclarecer o juízo moral comum, mas sim a faculdade prática da razão em sua relação com o conceito de dever (Cf. FMC, II, §11, BA36). Tratase de uma necessidade de passar à análise metafísica, afinal, é preciso garantir a origem a priori do princípio moral (Cf. FMC, II, §3, BA 27). Mas é preciso advertir para que não se conclua dessa necessidade reconhecida na II seção que a primeira tenha tratado o dever como um conceito empírico (Cf. FMC, II, §1, BA 25). A I seção passou do juízo moral comum ao juízo filosófico, mas não deixou o âmbito da filosofia moral popular, que ainda não garante a completa pureza dos princípios e conceitos, portanto, não ascendeu à metafísica: "uma tal Metafísica dos costumes, completamente isolada, [...] não é somente um substrato indispensável de todo o conhecimento teórico dos deveres seguramente determinado, mas também um desiderato da mais alta importância para a verdadeira prática das suas prescrições" (FMC, BA 33). Passamos então à discussão do imperativo categórico, como um dos princípios (logicamente) possíveis da vontade.

Os imperativos se dividem em duas classes. Os imperativos hipotéticos são aqueles que ordenam sob uma determinada condição. Não é que só deva reconhecer a validade dos imperativos quem tem uma condição específica de volição. Todos devem reconhecê-la se ele é realmente um imperativo, o que requer validade objetiva ou universal. Mas, obviamente, só está obrigado a obedecer o imperativo aquele que se encaixa na 
condição especificada, e não todo ser racional como tal. Não devemos também cometer o erro de achar que imperativos hipotéticos dependem de um desejo por um fim. Uma suposta vontade moral, que, portanto, não teria este tipo de dependência para agir, também precisaria de imperativos hipotéticos. Como vimos, esta vontade também tem fins empíricos e ela precisa empregar "todos os meios que as nossas forças disponham" (FMC, I, §3, BA 3, grifo meu) para alcançá-los.

A obrigação da vontade pensada em um imperativo hipotético é analítica. A vontade pode (e chega a) ser definida por Kant como a "faculdade dos fins" (CRPr, A103) e, em adição, o fundamento sobre o qual a razão deriva a ação necessária de uma lei é o seguinte princípio analítico ${ }^{6}$ : quem quer os fins quer (ou ao menos deve querer) os meios ${ }^{7}$. Isto quer dizer, uma lei diz: ações do tipo x são causas de y em circunstâncias z (uma lei teórica sintética, que, aliás, dá ensejo à Crítica da Razão Pura); a razão, com base no princípio analítico (um princípio hipotético e formal), pode inferir que: quem quer y, deve fazer $\mathrm{x}$ em circunstâncias z; no caso de seres dotados de uma vontade imperfeita; e que: quem quer y, faz x em circunstâncias z; no caso de uma vontade perfeita.

$O$ outro tipo de imperativo é o imperativo categórico. Este manda incondicionalmente e, devido a isto, a obrigação expressa por ele alcança qualquer ser racional, vale dizer, todo ser capaz de reconhecer uma lei, mas também que não segue estas leis necessariamente, ou não se trataria de um imperativo. Isto nos dá oportunidade de esclarecer por que Kant fala em seres racionais, e não em homens, quando se trata de estabelecer a vigência do princípio moral: "será da mais alta importância", ele diz, "advertir que não nos deve sequer passar pela idéia querer derivar a realidade deste princípio da constituição particular da natureza humana" (FMC, II, §42, BA 59). E acrescenta: "Se essa lei existe, então tem ela de estar já ligada (totalmente a priori) ao conceito da vontade de um ser racional em geral" (FMC, II, §45, BA 62). Como foi estabelecida a identidade entre uma lei incondicional e o princípio moral, ou seja, que o dever moral é aquele que manda incondicionalmente, então disto se segue que a moral deve ser válida não só para homens, que são seres racionais sob determinadas condições (sensivelmente afetados), mas para homens enquanto seres que podem reconhecer uma lei. Uma lei incondicional é o mesmo que uma lei cujo cumprimento é objetivamente necessário para todos a quem uma lei prática qualquer poderia se aplicar. Aplicá-la apenas à natureza humana seria, portanto, condicioná-la às nossas especificidades e contradizê-la.

A derivação da fórmula do imperativo categórico segue analiticamente de seu conceito. Como diz Kant: "se pensar um imperativo categórico, então sei imediatamente o que é que ele contém” (FMC, II, §30, BA51). Se o imperativo moral é aquele que expressa um princípio racional incondicional para a avaliação das máximas ou princípios subjetivos da vontade, então ele obriga que 0 sujeito possa querer que sua máxima valha para todo ser racional e não apenas para ele. Aqui, basta que entendamos o que significa para o sujeito estar racionalmente justificado a agir.

Não podemos nos considerar racionais, mesmo em um sentido mínimo, e, ao mesmo tempo, sustentar que não seria válido para outro em nosso lugar querer o mesmo que nós. Por exemplo, se para quem quer y é racional fazer x em determinadas circunstâncias, então qualquer outro que queira y também pode fazer x em circunstâncias iguais sob todos os aspectos relevantes.

Um princípio racional incondicional não restringe esse "teste" de racionalidade a uma determinada classe de seres racionais, àqueles que querem y. Por conseguinte, a fórmula desse princípio não deve conter nada que restrinja o âmbito da avaliação da racionalidade de uma ação, ou seja, o princípio seria o que resta de um princípio racional após a eliminação de todas as condições expressas nele ou a pura forma universal de uma lei racional a qual uma máxima deve se conformar: "Age apenas segundo uma máxima tal que possas a mesmo tempo querer que ela se torne lei universal” (FMC, II, §31, BA 52). Trata-se apenas da possibilidade de querer de forma consistente ou sem contradição a universalização de uma máxima $^{8}$ (Cf. FMC, II, §75, BA 81). O querer não pode inviabilizar suas condições lógicas quando universalizado ou não é um querer racional (adequado a todos).

A fórmula supracitada pode ser chamada: fórmula da lei universal. Ela decorre imediatamente do conceito de imperativo categórico ou incondicional, conforme está explicado acima. No entanto, existem outras quatro formulações do mesmo princípio moral. Uma delas é a fórmula do fim em si: "Age de tal maneira que uses a humani- 
O imperativo categórico como realização da necessidade lógica da razão

dade, tanto na tua pessoa como na pessoa de qualquer outro, sempre e simultan eamente como fim e nunca simplesmente como meio" (FMC, II, §49, BA 66-7). Se tomarmos esta fórmula isoladamente, temos apenas um conceito negativo de fim em si, um fim que não pode ser também um meio. Sabemos que não devemos nos utilizar de outros sujeitos ou de nossa própria vontade como simples meio, mas não sabemos em que tipo de máxima tomamos a humanidade também como um fim supremo. O conceito de fim em si é determinado positivamente quando nos servimos da fórmula da lei universal. O ser racional é um fim em si mesmo, na medida em que é capaz de agir segundo máximas universalizáveis, pois é somente nesta medida que sua vontade tem um valor incondicional (Cf. FMC, II, §49, BA 66 e §54, BA 70).

A autonomia, ou o "conceito segundo o qual todo o ser racional deve considerar-se como legislador universal por todas as máximas da sua vontade para [...]julgar a si mesmo e às suas ações" (FMC, II, §60, BA 74); é uma decorrência das duas formulações anteriores. Só podemos pensar em uma máxima como lei universal se a legislação de onde ela brota não é condicionada por interesses externos à razão prática, que são empíricos e, portanto, privados. Em outras palavras, máximas são universalizáveis se a vontade legisla para si mesma, independentemente de nossas necessidades sensíveis. Da mesma forma, só podemos pensar na vontade racional como fim em si se esta vontade não é meramente instrumentalizada, tendo em vista interesses alheios. Uma vontade heterônoma seria uma vontade boa apenas como meio para a obtenção de fins que não são os dela mesma, mas sim os da sensibilidade.

As três fórmulas citadas até aqui são conceituais. As duas restantes trazem analogias ou comparações. Servem para aproximar as fórmulas conceituais da intuição, daí a prioridade dessas últimas. A fórmula da lei da natureza diz: "Age como se a máxima da tua ação se devesse tornar, pela tua vontade, em lei universal da natureza" (FMC, II, §33, BA 52). Por fim, a fórmula do Reino dos Fins diz: “Age segundo máximas de um membro universalmente legislador em ordem a um reino dos fins somente possível” (FMC, II, §77, BA 84). Estas rápidas considerações vêm apenas a título de explicar a analiticidade da relação entre as fórmulas e a prioridade que demos e continuaremos a dar à formulação conceitual da lei universal ${ }^{1}$.
A lei moral como princípio analítico em relação a uma vontade perfeita

Sabemos que imperativos são princípios práticos objetivos pensados em relação a uma vontade racional imperfeita. No caso do imperativo categórico, a mesma fórmula, mas para uma vontade que não se especifica como sensivelmente afetada, é o que Kant chama apenas de lei moral. Assim, fala-se, não em imperativo, mas em lei moral, no caso do princípio ser pensado em relação a uma vontade perfeita, especificamente a que não é afetada pela sensibilidade, ou a uma vontade em geral, em que não se considera se é ou não afetada. Assim, a lei moral, embora tenha o mesmo conteúdo que o imperativo correspondente, se refere a conceitos significativamente diferentes de vontade, embora intrinsecamente relacionados.

Neste sentido, Guido de Almeida chama atenção para uma nota de rodapé da Fundamentação, em que Kant diz sobre o imperativo categórico que ele "não deriva analiticamente o querer de uma ação de um outro querer já pressuposto (pois nós não possuímos uma vontade tão perfeita)..." (FMC, II, nota ao §28, BA 51, grifo meu). Isto sugere que o conceito de vontade perfeita possa se ligar analiticamente à conformidade das máximas a uma lei universal, sendo assim a lei moral, para vontades perfeitas, um princípio analítico. A vontade racional perfeita parece idêntica a uma vontade puramente racional, sendo esta uma vontade que sempre conforma suas máximas a princípios racionais puros. A lei moral, por sua vez, como princípio incondicional, é equivalente a um princípio sem condições empíricas, ou puramente racional. Por conseguinte, a vontade perfeitamente racional é a vontade que age necessariamente sob a lei moral (ALMEIDA, 1998, p. 67).

Chegamos à analiticidade da relação da moral com a vontade perfeita apenas com o conceito de lei moral, mesmo sem a fórmula do princípio que, dada esta relação analítica apresentada, poderia ser deduzida também do conceito de uma vontade perfeitamente racional, e não só do conceito de um princípio incondicional. Entendendo o que significa dar razões, uma vontade que levasse isto à perfeição teria que terminar no teste de universalização expresso no princípio moral. Explicando, já que dar razões para uma ação, mesmo no sentido mínimo, é igual a mostrar que todo ser racional poderia fazer o mesmo no lugar do 
sujeito cuja ação se justifica, pois do contrário sua ação seria de valor meramente privado, se abrimos mão de um princípio incondicional, como não podemos regredir ao infinito, chegamos a um ponto em que não se pode mais dar razões.

Mesmo que seja concedido que todos que querem y têm boas razões para fazer $\mathrm{x}$ em circunstâncias $\mathrm{z}$, por que alguém poderia racionalmente querer y, a não ser que fosse algo que pudesse ser válido como uma lei universal para todo ser racional enquanto tal? O que resta ao sujeito, sem o princípio incondicional, é dizer: eu quero, porque desejo. Trata-se de um sujeito como o do exemplo com o qual Allison (1990, p. 206), um opositor desta tese, ilustra sua objeção. Ele não pode manter sua racionalidade. Ele pode, como egoísta racional, dizer que agiu em prol de seus interesses com os meios que todo agente racional tem razões para empregar. Entretanto, se perguntarmos por que ele tem tais interesses, ou ele recorre a uma constatação de fato sobre sua natureza e deixa, portanto, de se justificar, ou ele tenta demonstrar que todo sujeito racional pode perseguir o mesmo fim que ele, o que implica dizer que a máxima que expressa este fim pode ser querida como lei universal.

\section{A questão da sinteticidade do imperativo categórico}

Agora, cabe perguntar se o imperativo categórico, o mesmo princípio, mas pensado em relação ao conceito de uma vontade imperfeitamente racional, não é também analítico, ou seja, se a lei moral, em relação à vontade em geral, não é analiticamente válida. Guido de Almeida ressalta que, se por imperfeição da vontade queremos dizer que ela é falível, no sentido em que ela pode desviar-se do princípio que reconhece perante a pressão de suas inclinações, então não há por que pensar na validade do princípio como sintética (1998, p. 69). A simples mudança da lei para a forma imperativa resolve o problema. È neste sentido que Paton diz que "nós podemos passar sem dificuldade de um princípio objetivo incondicionado da ação para um imperativo categórico" (1947, p.199, 247). Mas, ao que tudo indica, não é só esta a imperfeição possível da vontade.

Nós não podemos pensar uma vontade perfeita que não reconhece um princípio perfeita- mente racional. Todavia, nós podemos pensar uma vontade imperfeita no sentido de uma vontade que não reconhece 0 princípio puramente racional ${ }^{10}$. Ela continua sendo uma vontade, porque age sob princípios. Como esses princípios podem ser apenas os condicionados, não decorre do conceito de vontade imperfeita o reconhecimento da lei moral. Pode-se pensar então que, pelas mesmas razões, não decorreria do conceito de vontade em geral que ela tenha que seguir um princípio incondicionado. Por isso, o princípio moral, na medida em que tem que viger para toda e qualquer vontade, e não só para uma vontade em específico, como a perfeita, seria sintético.

É neste ponto que gostaria de introduzir uma reflexão divergente. De fato, o reconhecimento do princípio moral tal qual formulado por Kant não decorre do conceito de vontade em geral. No entanto, essa falibilidade cognitiva não parece ser a chave para a classificação do tipo de relação do princípio para com a vontade. O sujeito que não segue o imperativo categórico por não reconhecêlo não é imputável. Ao menos momentaneamente, o discurso moral não diz respeito a ele ${ }^{11}$. Mas em relação a este indivíduo, o ponto crucial para a determinação do tipo de relação (analítica ou sintética) existente entre sua vontade e o princípio moral parece ser a existência ou não de razões inerentes à própria fórmula do princípio para tal reconhecimento, e não o reconhecimento efetivo ou não do dever, que é contingente.

Se a própria compreensão adequada do princípio moral já o impuser ao indivíduo, ainda que este seja dotado de uma vontade imperfeita, não há porquê considerarmos a universalização das máximas como uma exigência sintética em relação à vontade em geral, apenas em virtude dessa compreensão adequada ser contingente para vontades imperfeitas. A validade de um princípio qualquer, analítico ou sintético, não é influenciada por seu reconhecimento efetivo por parte de sujeitos empíricos. A matemática não deixa de ser universalmente válida se determinados indivíduos ainda não aprenderam sequer suas operações básicas. No caso da moral, a ausência de reconhecimento afeta a imputabilidade, mas este é um problema diferente em relação à validade do próprio dever. Esta separação entre os problemas torna-se ainda mais evidente quando nos damos conta de que uma eventual dedução do princípio moral, tomado então como princípio sintético, não visa 
de modo algum estabelecer que vontades imperfeitas reconhecem o imperativo categórico, mas tão somente que ele é válido e, portanto, há razões para que o sujeito imperfeito o reconheça. $\mathrm{O}$ reconhecimento em si é simplesmente uma questão factual e, conseqüentemente, sempre contingente e alheio a provas a priori. Com estas considerações feitas, passo a argumentar que a própria filosofia kantiana demonstra que as razões para 0 reconhecimento da necessidade de obediência a um princípio incondicional decorrem do conceito de uma vontade racional em geral.

\section{O Imperativo Categórico e o Postulado Lógico da Razão}

A razão, no seu uso lógico, procura a condição geral do seu juízo (da conclusão) e o raciocínio não é também mais do que um juízo obtido, subsumindo a sua condição numa regra geral (a premissa maior). Ora, como esta regra, por sua vez, está sujeita à mesma tentativa da razão e assim (mediante um pro-silogismo) se tem de procurar a condição da condição, até onde for possível, bem se vê que o princípio próprio da razão em geral (no uso lógico) é encontrar, para o conhecimento condicionado do entendimento, o incondicionado pelo qual se lhe completa a unidade (CRP, A 307 B 364, cf. também A 332 B 389).

Da forma citada, ao examinar o "procedimento formal e lógico da razão", Kant expõe a "máxima lógica", que determina a necessidade da razão de buscar a condição incondicionada para todo condicionado dado. Segundo Kant, é uma exigência lógica "admitir premissas completas para uma dada conclusão" (CRP, A 500 B 528). A análise que Beck faz da terminologia lógica de Kant facilita ainda mais a compreensão da tese kantiana: "foi seu costume [de Kant] chamar a premissa maior em um silogismo de primeira figura um princípio (algumas vezes, uma regra) e seu termo médio (o sujeito da premissa), ele chamava a condição" (1960, p. 81).

Deste modo, é simples compreender que a razão, frente a uma proposição como "C é B", procura por sua justificativa - o que é o mesmo que dizer: pela condição de sua validade - montando um silogismo que estabelece que "C é B", porque "C é A" e "A é B", ou seja: "A é B", "C é A", portanto, "C é B". Mas isto não significa que a razão tenha realizado sua tarefa e justificado a proposição " $\mathrm{C}$ é B" pela mera descoberta da condição " $A$ " de sua validade, porque este mesmo raciocínio não estabelece a validade do princípio "A é $B$ ", restando que "C é B" pode ser apresentado apenas como uma hipótese. Assim, o problema se recoloca: a razão está frente a uma proposição, "A é B", que deve ser a conclusão de um outro raciocínio, cuja condição deve ser descoberta. Fica assim demonstrado que a razão só pode se satisfazer (justificar "C é B") se e quando chegar a uma condição incondicionada, sendo a busca desta condição uma necessidade analítica imposta por sua natureza e incontornável:

A proposição que se segue é clara e indubitavelmente certa: quando o condicionado é dado, é-nos proposta, como tarefa, uma regressão na série total das condições do mesmo; porque o conceito de condicionado já implica que algo se refira a uma condição e se esta, por sua vez, for condicionada, que se refira a outra mais distante e assim sucessivamente através de todos os elementos da série. Esta proposição é, por conseguinte, analítica e está ao abrigo de qualquer crítica transcendental. É um postulado lógico da razão (CRP, A 497-8 B 526).

No uso teórico da razão, o postulado lógico é convertido apenas em princípio regulativo (metodológico) para conduzir à máxima extensão e unidade do sistema de conhecimentos empíricos, isto porque todos os fenômenos, únicos referentes possíveis para conceitos teónicos constitutivos (objetivos), são eventos sempre condicionados e efetivos apenas na medida em que a síntese entre eles é realizada pelo sujeito do conhecimento, não podendo jamais, portanto, ser completada uma série de condições sensíveis. Com isso em mente, sabemos que não é lícito à razão esperar de objetos sensíveis uma concordância com sua necessidade lógica pelo incondicionado. (Cf. CRP, A 306 B 3623, A 309 B 365-6, B 409 e A 510 B 538).

No entanto, se não posso transpor para o mundo dos objetos sensíveis o que é apenas uma necessidade lógica da razão, quando a própria razão é a criadora da série de condições, por meio do poder causal de uma vontade, sua máxima lógica torna-se enfim constitutiva (Cf. CRP, A 301-2 B 358). Neste sentido, notamos que nossa 
sugestão neste artigo não é tão heterodoxa quanto parecia à primeira vista, pois é o próprio Kant quem nos indica o caminho:

Resta-nos ainda investigar, depois de negado à razão especulativa qualquer processo neste campo do supra-sensível, se no domínio do conhecimento prático não haverá dados para determinar esse conceito racional transcendente do incondicionado [...]. Deste modo, a razão especulativa concede-nos, ainda assim, campo livre para essa extensão, embora o tivesse que deixar vazio, competindo-nos a nós preenchê-lo, se pudermos, com os dados práticos, ao que por ela mesmo somos convidados (CRP, B XXI)

Este artigo tão somente atende ao convite da razão ao tratar o imperativo categórico como sua realização, o que também o próprio Kant faz na Crítica da Razão Prática:

Fica também agora solidamente estabelecida a liberdade transcendental [correlato analítico recíproco do imperativo categórico] e tomada, sem dúvida, no sentido absoluto de que a razão especulativa precisava [...] ela quer pensar o incondicionado, mas só podia estabelecer esse conceito problematicamente, como não impossível de pensar [...]. O conceito de liberdade, na medida em que sua realidade é demonstrada por uma lei apodíctica da razão prática, constitui a pedra angular de todo o edifício de um sistema da razão pura, mesmo da razão especulativa (A 4, cf. também A 189, A 194 e CRP A 552 B 580)

Com essas passagens abordadas, tornase mesmo trivial apontar o imperativo categórico como uma realização do postulado lógico da razão, cabe então a ponderação do impacto desta análise para uma possível justificativa intrínseca da fórmula da lei moral. Aqui, defendemos que, por sua própria formulação racional incondicional, o imperativo categórico já seria inerente às exigências do funcionamento de qualquer razão que queira se apresentar enquanto tal, contendo, portanto, em si mesmo sua justificativa.

\section{Considerações finais}

Podemos pensar em um indivíduo racional que opte pela realização de suas inclinações em detrimento de sua racionalidade. Podemos pensar em um indivíduo racional que não reconheça efetivamente um princípio objetivo supremo para a avaliação de suas máximas. Mas não podemos pensar em um indivíduo dotado de vontade racional, portanto, de uma capacidade para realizações conforme a princípios racionais, que possa, por opção ou ignorância, interromper uma série de justificativas ofertadas como abono de suas ações, antes de alcançar um princípio incondicionado, e, ainda assim, satisfazer sua própria razão na tarefa de legitimar sua conduta. A lei moral, na medida em que representa uma condição incondicionada para máximas (e, por conseguinte, para ações), se impõe analiticamente a partir do momento em que um indivíduo se engaja na tarefa de argumentar em prol de seus feitos, porque este exercício consiste no desenvolvimento de um pro-silogismo cuja interrupção pode ser escolhida, mas não pode ser autorizada pela razão, visto que ela mesma está fornecendo os elementos da série de condições e não pode contrariar sua própria natureza.

\section{Notas}

2 “Todos os princípios (Prinzipien) práticos que pressupõe um objeto (Objekt) (matéria) da faculdade de desejar, enquanto princípio determinante da vontade, são no seu conjunto empíricos e não podem fornecer nenhumas leis práticas" (CRPr, A 38).

3 Paton coloca a este respeito que: "Kant não é tão tolo para negar que uma ação feita por dever produzirá resultados e procurará produzir resultados. Ela sempre procura produzir resultados, e normalmente tem sucesso em fazê-lo. Tudo que Kant está dizendo é que seu valor distintivamente moral não depende dos resultados procurados ou dos resultados alcançados" (1947, p. 58-9).

4 "Essa característica formal das minhas ações (subordinação das mesmas ao princípio da validade universal) no que somente reside o seu valor moral intrínseco, está completamente em nosso poder..." (CFJ, §91, nota à B 461).

5 Um bem incondicional tem que ser um conceito extraído de um princípio, pois se for extraído de um sentimento, será subjetivo, ou seja, nem sequer universal, quem dirá incondicional (Cf. CRPr, A 101-3, para maiores esclarecimentos).

6 "Kant deveria dizer, portanto, não que o imperativo hipotético é analítico, mas que seu princípio formal [...] é analítico. Ele sozinho concerne à vontade de um ser racional independentemente do conteúdo cognitivo..." (Beck, 1960, p. 87). Na verdade, Kant também esteve consciente disto: "para determinar os próprios meios para alcançar uma intenção proposta são já precisas na verdade proposições sintéticas, que não dizem porém respeito ao princípio, mas ao objeto a realizar" (FMC, II, §24, BA 45. Cf. também Paton, 1947, p. 126).

7 "Kant deveria dizer, portanto, não que o imperativo hipotético é analítico, mas que seu princípio formal [...] é analítico. Ele sozi- 
nho concerne à vontade de um ser racional independentemente do conteúdo cognitivo..." (Beck, 1960, p. 87). Na verdade, Kant também esteve consciente disto: "para determinar os próprios meios para alcançar uma intenção proposta são já precisas na verdade proposições sintéticas, que não dizem porém respeito ao princípio, mas ao objeto a realizar" (FMC, II, §24, BA 45. Cf. também Paton, 1947, p. 126).

8 Ora, uma máxima geralmente expressa as circunstâncias de sua aplicação. Só as mais gerais são aplicáveis em qualquer contexto. Assim, aparentemente, quando uma máxima é testada tem-se: 1) a candidata à máxima - eu quero $\mathrm{x}$, então eu quero fazer y em circunstâncias z; 2) a submissão ao teste de universalização todos os seres racionais (não só os que querem $\mathrm{x}$ ) podem querer fazer y em circunstâncias z. Esta observação parece útil, uma vez que há uma propensão para que se pense em uma ética universal como uma ética que não permite ao sujeito considerações referentes ao contexto em que a ação é executada.

9 Toda esta análise tem um grande débito para com Guido de Almeida (2001).

10 "O imperativo diz-me, pois, que ação das que me são possíveis seria boa, e representa a regra prática em relação com uma vontade, que não pratica imediatamente uma ação só porque ela é boa, em parte porque o sujeito nem sempre sabe que ela é boa..." (FMC, II, §18, BA 40, grifo meu).

11 É interessante lembrarmos com Beck que a "verdadeira moralidade pode surgir quando a razão, gradualmente aperfeiçoada como um instrumento, torna-se consciente de sua vocação mais alta" (1966, p. 234)

\section{Referências}

Obras de Kant:

Edição alemã:

Immanuel Kant: Werke in Zwölf Bande. Ed. W. Weischedel. Frankfurt : Surkamp, 1991.
Traduções:

Crítica da Razão Pura. Trad. Manuela Pinto dos Santos; Alexandre Fradique Morujão. 4 ed. Lisboa : Calouste Gulbenkian, 1997.

Crítica da Razão Prática. Trad. Artur Morão. Lisboa : Edições 70, 1997.

Fundamentação da Metafísica dos Costumes. Trad. Paulo Quintela. Lisboa : Edições 70, 2000.

Obras sobre Kant:

ALLSON, Henry. Kant's Theory of Freedom. New York: Cambridge University Press, 1990.

ALMEIDA, Guido A. de. "Kant e o 'Facto da Razão': 'Cognitivismo' ou 'Decisionismo' Moral?' Studia Kantiana, 1 (1) : 53-81, 1998.

"As Fórmulas do Imperativo Categórico". In: III CONGRESSO KANT. Itatiaia, 2001.

BECK, Lewis W. A Commentary on Kant's Critique of Practical Reason. Chicago: The University of Chicago Press, 1960.

PATON, H. J. The Categorical Imperative: a study in Kant's moral philosophy. London: Hutchinson, 1947.

Recebido em 20/08/2003

Aprovado em 01/10/2003 